\title{
Comparing primary care Interprofessional and non-interprofessional teams on access to care and health services utilization in Ontario, Canada: a retrospective cohort study
}

\author{
Wissam Haj-Ali ${ }^{1,2,3,4^{*}}$, Brian Hutchison ${ }^{5}$, Rahim Moineddin ${ }^{1,2,4,6}$, Walter P. Wodchis ${ }^{1,2,4,7}$ and
} Richard H. Glazier ${ }^{1,2,4,6,8}$

\begin{abstract}
Background: Many countries, including Canada, have introduced primary care reforms to improve health system functioning and value. The purpose of this study was to examine the association between receiving care from interprofessional primary care teams and after-hours access to care, patient-reported walk-in clinic visits and emergency department use.

Methods: We conducted a retrospective cohort study linking population-based administrative databases to Ontario's Health Care Experience Survey (HCES) between 2012 and 2018. We adjusted for physician group characteristics as well as individual physician and patient characteristics while assessing the relationship between receiving care from interprofessional teams and the outcomes of interest.

Results: As of March 31st, 2015, there were 465 physician groups with HCES respondents of which 177 (38.0\%) were interprofessional teams and 288 (62.0\%) were non-interprofessional teams in the same blended capitation reimbursement model. In this period, there were 4518 physicians with HCES respondents, of whom 2131 (47.2\%) were in interprofessional teams and 2387 (52.8\%) were in non-interprofessional teams. There were 10,102 HCES respondents included in this study, of whom $42.4 \%$ were in interprofessional teams and $42.3 \%$ were in noninterprofessional teams. After adjustment, we found that being in an interprofessional team was associated with an increase in the odds of patients reporting same/next day access to care by $12.0 \%(\mathrm{OR}=1.12 \mathrm{Cl}=1.00$ to $1.24 p$ value 0.0436$)$ and a decrease in the odds of patients reporting walk-in clinic use by $16 \%(\mathrm{OR}=0.84 \mathrm{Cl}=0.75$ to 0.94 $p$-value 0.0019). After adjustment, there were no significant differences in patient-reported after-hours access to care and emergency department use.
\end{abstract}

\footnotetext{
* Correspondence: Wissam.haj.ali@mail.utoronto.ca

'Dalla Lana School of Public Health, Toronto, Ontario, Canada

${ }^{2}$ Institute of Health Policy, Management and Evaluation, University of

Toronto, 155 College Street, Toronto, Ontario M5T 3M6, Canada

Full list of author information is available at the end of the article
}

(c) The Author(s). 2021 Open Access This article is licensed under a Creative Commons Attribution 4.0 International License, which permits use, sharing, adaptation, distribution and reproduction in any medium or format, as long as you give appropriate credit to the original author(s) and the source, provide a link to the Creative Commons licence, and indicate if changes were made. The images or other third party material in this article are included in the article's Creative Commons licence, unless indicated otherwise in a credit line to the material. If material is not included in the article's Creative Commons licence and your intended use is not permitted by statutory regulation or exceeds the permitted use, you will need to obtain permission directly from the copyright holder. To view a copy of this licence, visit http://creativecommons.org/licenses/by/4.0/. The Creative Commons Public Domain Dedication waiver (http://creativecommons.org/publicdomain/zero/1.0/) applies to the data made available in this article, unless otherwise stated in a credit line to the data. 
Conclusions: Ontario has invested heavily in interprofessional primary care teams. As compared to patients in noninterprofessional teams, patients in interprofessional teams self-reported more timely access to care and less walk-in clinic use but no significant difference in self-reported access to after-hours care or in emergency department use. For jurisdictions aiming to expand physician voluntary participation in interprofessional teams, our study results inform expectations around access to care and health services utilization.

Keywords: Primary care, Interprofessional teams, Patient experience, Access, Health services utilization

\section{Background}

Moving towards value-based healthcare is a priority for healthcare systems internationally [1]. The pursuit of providing value-based health care revolves around three aims: improving the experience of care, improving the health of populations, and reducing per capita costs [2]. A strong primary care system is recognized as the cornerstone of health systems and is associated with better outcomes, improved patient experience and lower cost [3]. Many countries around the world, including Canada, have introduced primary care reform to deliver on those goals.

During the economic recession in the 1990s, there has been limited investments in primary care innovation in Canada [4]. A decade later, primary care reform initiatives started to emerge in Canada in response to various recommendations from federal and provincial committees $[5,6]$. In line with the Canadian healthcare reform movement, Ontario has undergone three major primary care policy initiatives: new physician payment and governance models, enrolment of patients with a primary care physician and support for the development of interprofessional teams [7]. Interprofessional teams are "groups of professionals from different disciplines who communicate and work together in a formal arrangement to care for a patient population in a primary care setting." [8] They typically include primary care physicians, nurses or nurse practitioners, and at least one other health care professional (e.g. pharmacist, social worker, dietitian or physiotherapist). Interprofessional teams are also eligible for funding an administrator or executive director.

During the last 20 years, more than $30 \%$ of primary care physicians have willingly moved from fee-forservice payment model to a blended capitation. Some of those physicians have received extra funding to set up and deliver interprofessional team-based care. Currently, the dominant blended capitation model in Ontario is called Family Health Organization (FHO). FHOs have formal patient enrollment, electronic medical records, physician-led governance and a minimum of three physicians practicing together. They offer comprehensive care, including preventive health care services, chronic disease management and health promotion, through a combination of regular physician office hours and after- hours services. FHOs were eligible to apply for additional funding for allied health professionals to join their practice and become interprofessional primary care teams called Family Health Teams.

The government's priorities in establishing interprofessional teams were to increase access to primary care and appropriate healthcare services utilization [9]. Physicians in FHO models in Ontario are required to provide afterhours access to care and receive a bonus when their patients do not seek services from physicians outside of their group, such as in walk-in clinics. The bonus is not affected if their patients visit the emergency department. Interprofessional team-based care is thought to free up some of the physicians' time by delegating tasks to other health care professionals within their scope of practice [10]. Access to quality primary care can reduce the need for unnecessary and more expensive services [11]. Treating less-urgent conditions in primary care could improve continuity of care and patient experience [12, 13].

Several studies conducted in Ontario have compared capitation-based interprofessional teams to other funding and delivery models of care on specific measures of quality [14-20]. However, little research to date has evaluated the association between the interprofessional aspect of primary care teams and access to care and health services utilization. Our study examined the association between receiving care from interprofessional versus non-interprofessional primary care teams and patient-reported timely and after-hours access to care, patient-reported walk-in clinic visits and emergency department use. We hypothesised that interprofessional teams would be better performers on these measures given their enhanced capacity and structure. Evidence from our setting that underwent large-scale primary care reform will be relevant to other jurisdictions contemplating innovations in primary care delivery and, specifically, the adoption of interprofessional team-based primary care.

\section{Methods}

\section{Setting}

Ontario is a province in Canada and had a population on 14.7 million people in 2020 [21]. Permanent residents of Ontario are fully insured for physician primary care services through the Ontario Health Insurance Plan 
(OHIP) with no co-payment or deductible. Primary care organization and payment models have evolved over the course of the last 18 years. Three dominant practice models exist in Ontario-enhanced fee-for-service, nonteam blended capitation and team-based blended capitation. These models are described in detail elsewhere [7, $22,23]$.

The focus of this study was on the dominant blended capitation model-FHO-within which physicians practice in either interprofessional or non-interprofessional teams. When patients seek primary care services outside the practice in which they are enrolled, for example in walk-in clinics, the FHO loses a bonus payment equal to the fee-for-service payments to the physician who treated the patient, to a maximum bonus of $18.59 \%$ of the practice's total capitation [24]. There is no deduction if an enrolled patient visits an emergency department for non-emergency care. FHOs are required to provide at least one three-hour block of after-hours services per week for each physician in the group, to a maximum of five three-hour blocks per week for practices with five or more physicians. Contracts define "after-hours" as Monday to Thursday after 5 p.m. or any time on the weekend-that is, any time from Friday after $5 \mathrm{pm}$ through Sunday [25].

\section{Design and population}

We conducted a retrospective cohort study where we linked several population-based administrative databases to the Health Care Experience Survey (HCES) using encoded identifiers at ICES (formerly known as the Institute for Clinical Evaluative Sciences) to form data extractions and identify the population of interest (Fig. 1). The HCES is collects information to understand

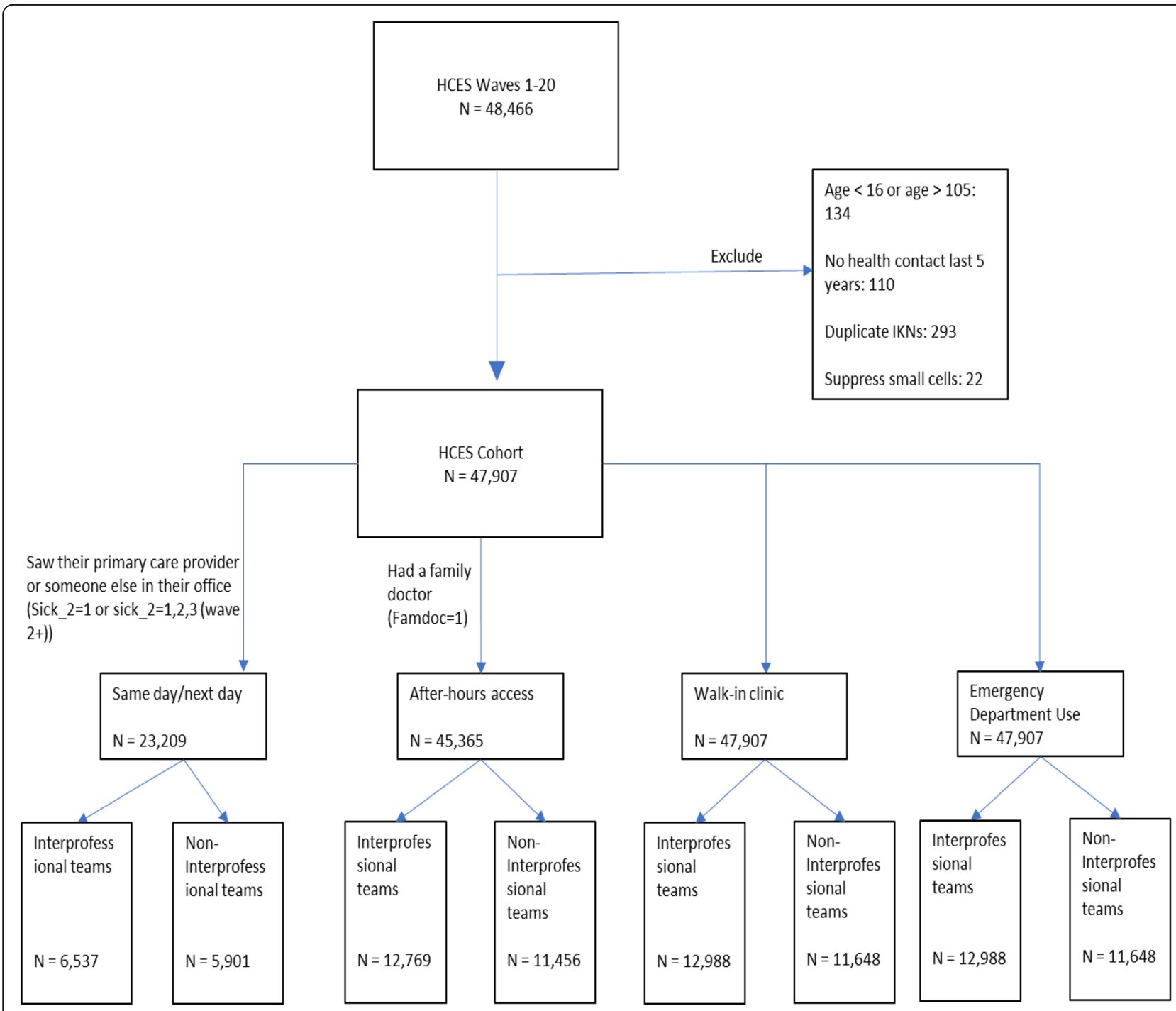

Fig. 1 Study population flow diagram 
Ontarians' experience in obtaining primary care services and helps the Ministry of Health in planning health care programs and policies. The HCES survey is conducted continuously by the Institute for Social Research (ISR) at York University, with data being provided to the Ontario Ministry of Health every 3 months (termed a 'wave').

The study population comprised respondents to the HCES over six fiscal years (April 1 - March 31) from 2012/13 to 2017/18. The HCES targets persons 16 years and older who live in private dwellings in Ontario. People living in institutions, in households without telephones are excluded. The study included respondents from 20 quarterly waves of the HCES that were conducted between October 2012 and October 2017. The average response rate was $51 \%$ during that period. Once households were sampled in the HCES, they were removed from the sampling frame for 2 years. Respondents who responded to the survey more than once throughout the study period were excluded.

For each of the data extractions, we identified respondent to the HCES at the end of the fiscal year. To be included in the study, respondents had to be consistently in an FHO blended capitation model throughout the observation period for the fiscal year they responded to the HCES. We captured patients' characteristics at the beginning of the fiscal year they responded to the HCES. Self-reported timely access to care, after-hours access to care and walk-in clinic visits were captured during the fiscal year the patient responded to the HCES and ED visits were captured at the end of that fiscal year from health administrative data. Physician group and physicians' characteristics were captured at the midpoint of the study timeframe, March 31st, 2015 (Fig. 2).

\section{Measures and data sources \\ Exposure}

Enrolment in a FHO blended capitation model, with an interprofessional team was the exposure. The exposure variable was retrieved from a population and demographics database-the Client Agency Program Enrolment tables that identify the patient enrolment model and the physician with whom patients are enrolled. A separate file provided by the Ontario Ministry of Health $(\mathrm{MOH})$ to ICES identified physicians who are part of an interprofessional team versus a non-interprofessional team.

\section{Outcomes}

The outcomes included patient-reported timely access to care, patient-reported after-hours access to care,

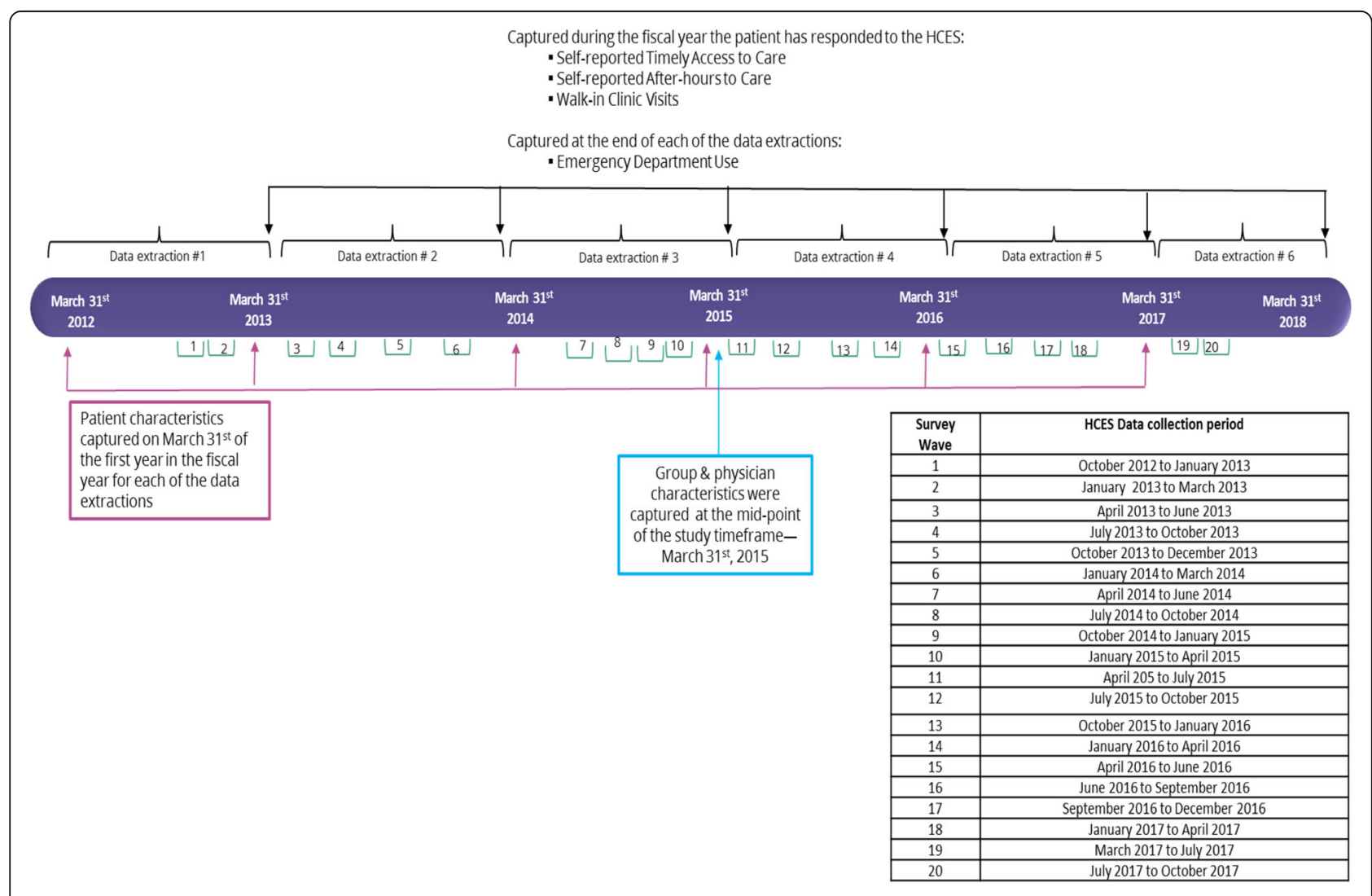

Fig. 2 Data extractions and cohort generation 
Table 1 Physician Group and physicians characteristics (on March 31st, 2015) - comparing HCES respondents in interprofessional teams to respondents in non-interprofessional teams

\begin{tabular}{|c|c|c|c|c|}
\hline Physician Group characteristics & \multicolumn{2}{|c|}{ Interprofessional Teams } & \multicolumn{2}{|c|}{ Non-interprofessional teams } \\
\hline Physician Groups No. (\%) & 177 & 38.0 & 288 & 62.0 \\
\hline Number of physicians per group, Mean (SD) & 13.1 & 10.7 & 8.8 & 7.6 \\
\hline Years under the capitation model, Mean (SD) & 6.0 & 3.0 & 4.2 & 2.6 \\
\hline \multicolumn{5}{|l|}{ Physicians characteristics } \\
\hline Physicians No. (\%) & 2131 & 47.2 & 2387 & 52.8 \\
\hline Number of patients per physician, Mean (SD) & 1366 & 615.1 & 1555 & 665.2 \\
\hline \multicolumn{5}{|l|}{ Sex No. (\%) } \\
\hline Female & 987 & 46.3 & 1045 & 43.8 \\
\hline \multicolumn{5}{|l|}{ Age group in Yrs. No. (\%) } \\
\hline$<40$ & 329 & 15.4 & 222 & 9.3 \\
\hline $40-64$ & 1417 & 66.5 & 1607 & 67.3 \\
\hline$>64$ & 358 & 16.8 & 534 & 22.4 \\
\hline Missing & 27 & 1.3 & 24 & 1.0 \\
\hline \multicolumn{5}{|l|}{ Country of medical graduation Canada No. (\%) } \\
\hline Yes & 1724 & 80.9 & 1775 & 74.4 \\
\hline \multicolumn{5}{|l|}{ Years in practice No. (\%) } \\
\hline$<5$ & 47 & 2.2 & 41 & 1.7 \\
\hline 5_15 & 620 & 29.1 & 420 & 17.6 \\
\hline $16-25$ & 495 & 23.2 & 606 & 25.4 \\
\hline$>25$ & 969 & 45.5 & 1320 & 55.3 \\
\hline Missing & 0 & 0 & 0 & 0 \\
\hline
\end{tabular}

patient-reported walk-in clinic use and emergency department use. Patient-reported timely access to care, after-hours access to care and walk-in clinic use were derived from the HCES (How many days did it take from when you first tried to see your provider to when you actually saw them or someone else in their office? (sick_3); The last time when you needed medical care in the evening, on a weekend, or on a public holiday, how easy or difficult was it to get care without going to the emergency department? (access_5); Have you been to a walk-in clinic because you were sick or for a healthrelated problem in the 12 months? (wi_1)). The HCES is a quarterly survey of a random sample of the Ontario population, 16 years and older, conducted on behalf of the $\mathrm{MOH}$ by the Institute for Social Research at York University. The survey focuses on Ontarians' primary care experience, including access to care, to generate regional and province-level data. The National Ambulatory Care Reporting System (NACRS) was used to derive emergency department visits.

\section{Physicians, physicians groups and patient characteristics} All characteristics were derived from administrative databases available at ICES. Physicians' characteristics included age, sex, years since graduation, Canadian graduate status and number of years in practice. Physician group characteristics included the number of physicians per group and number of years under the capitation model.

Patient characteristics included age, sex and OHIP registration (as proxy for immigration), neighborhood income quintiles, rurality, and Resource Utilization Bands [26, 27].

\section{Analysis}

For the descriptive results, we generated counts and percentages for categorical variables and means and standard deviations for continuous variables to describe the characteristics of physician groups and physicians who were either in interprofessional or non-interprofessional teams in relation to the outcomes of interest. For the patient variables, we generated sample weighted descriptive statistics. The probability weights assigned to respondents in the HCES were dependent on the probability of being selected, which was determined from the sampling design.

For the outcomes, we ran sample weighted survey logistic regressions to model each of the outcomes while adjusting for the respective physician group, physician and patient characteristics. 
Table 2 Patients' characteristics comparing HCES respondents in interprofessional teams to respondents in non-interprofessional teams in the year they responded to the survey

\begin{tabular}{|c|c|c|c|c|}
\hline \multirow[b]{2}{*}{ Patients total } & \multicolumn{2}{|c|}{ Interprofessional Teams } & \multicolumn{2}{|c|}{ Non-interprofessional Teams } \\
\hline & 12,988 & 52.7 & 11,648 & 47.3 \\
\hline \multicolumn{5}{|l|}{ Sex No. (\%) } \\
\hline Female & 7678 & 57.6 & 6856 & 57.7 \\
\hline \multicolumn{5}{|l|}{ Age group, yr. No. (\%) } \\
\hline $16-44$ & 3819 & 33.0 & 3653 & 34.9 \\
\hline $45-64$ & 5272 & 42.4 & 4661 & 41.4 \\
\hline $65-84$ & 3602 & 23.1 & 3071 & 22.1 \\
\hline $84+$ & 295 & 1.5 & 263 & 1.6 \\
\hline Missing & 0 & 0 & 0 & 0 \\
\hline New OHIP registrants (within 10 years) No. (\%) & 355 & 3.1 & 460 & 5.1 \\
\hline \multicolumn{5}{|l|}{ Income quintile, No. (\%) } \\
\hline 1 (low) & 2089 & 13.8 & 1764 & 13.9 \\
\hline 2 & 2468 & 18.6 & 2228 & 17.9 \\
\hline 3 & 2697 & 21.2 & 2295 & 19.6 \\
\hline 4 & 2822 & 22.8 & 2550 & 22.0 \\
\hline 5 (high) & 2888 & 23.3 & 2784 & 26.4 \\
\hline Missing & 24 & 0.3 & 27 & 0.2 \\
\hline \multicolumn{5}{|l|}{ Rurality Index of Ontario, No. (\%) } \\
\hline Largest Urban (0) & 3759 & 33.6 & 4000 & 42.6 \\
\hline Large urban (1 to 9) & 2388 & 17.1 & 4078 & 29.4 \\
\hline Small-urban (10 to 39) & 4823 & 34.2 & 2737 & 21.7 \\
\hline Rural $(\geq 40)$ & 1892 & 14.4 & 763 & 5.8 \\
\hline Missing & 126 & 0.7 & 70 & 0.4 \\
\hline \multicolumn{5}{|l|}{ Resource utilization band (RUB), No. (\%) } \\
\hline 1 & 629 & 5.4 & 471 & 4.3 \\
\hline 2 & 2128 & 17.7 & 1802 & 16.5 \\
\hline 3 & 6746 & 51.0 & 6417 & 54.6 \\
\hline 4 & 2031 & 15.0 & 1869 & 15.4 \\
\hline 5 (very high user) & 823 & 5.4 & 674 & 5.1 \\
\hline Non-user and Missing & 631 & 5.5 & 415 & 4.2 \\
\hline \multicolumn{5}{|l|}{ Patients with Chronic disease } \\
\hline 2 + Co-morbidity No. (\%) & 6096 & 42.6 & 5628 & 44.3 \\
\hline 3+ comorbidities No. (\%) & 3482 & 23.3 & 3207 & 24.5 \\
\hline 4+ comorbidities No. (\%) & 1828 & 11.9 & 2686 & 12.4 \\
\hline 5+ comorbidities No. (\%) & 894 & 5.8 & 791 & 6.1 \\
\hline
\end{tabular}

All study analyses were conducted using SAS v.9.3 and statistical significance was assessed at a $p$-value $<0.05$.

\section{Results}

Baseline group, physician and patient characteristics comparing HCES respondents in interprofessional teams versus non-interprofessional teams

As of March 31st, 2015, there were 465 FHO physician groups with HCES respondents of which 177 (38\%) were interprofessional teams and 288 (62\%) were noninterprofessional teams. Interprofessional teams with HCES respondents had more physicians per group as compared to non-interprofessional teams $($ means $=13.1$ versus 8.84 , respectively) and more years under the capitation model (means $=6.0$ versus 4.3 respectively).

In this period, there were $4518 \mathrm{FHO}$ physicians with HCES respondents of whom 2131 (47.2\%) were practicing in interprofessional teams and 2387 (52.8\%) were practicing 
Table 3 Patient-reported timely access to care (same/next day) in the year patients responded to the HCES by physicians' characteristics identified on March 31st, 2015

\begin{tabular}{|c|c|c|c|c|}
\hline & \multicolumn{2}{|c|}{ Interprofessional Teams } & \multicolumn{2}{|c|}{ Non-interprofessional Teams } \\
\hline & Denominator & Percentage & Denominator & Percentage \\
\hline \multicolumn{5}{|c|}{ Physicians characteristics } \\
\hline \multicolumn{5}{|l|}{ Sex } \\
\hline Female & 2621 & 39.5 & 2256 & 35.5 \\
\hline Male & 3880 & 39.3 & 3614 & 37.4 \\
\hline Missing & 36 & 19.4 & 31 & 29.0 \\
\hline \multicolumn{5}{|l|}{ Age group } \\
\hline$<40$ & 761 & 40.6 & 433 & 33.5 \\
\hline $40-64$ & 4381 & 39.1 & 3973 & 35.9 \\
\hline$>64$ & 1243 & 40.3 & 1369 & 40.6 \\
\hline Missing & 152 & 27.6 & 126 & 25.4 \\
\hline \multicolumn{5}{|c|}{ Country of medical graduation Canada } \\
\hline No & 1176 & 36.6 & 1318 & 35.9 \\
\hline Yes & 5209 & 40.2 & 4457 & 37.2 \\
\hline Missing & 152 & 27.6 & 126 & 25.4 \\
\hline \multicolumn{5}{|c|}{ Years in practice } \\
\hline$<5$ & 151 & 35.1 & 110 & 30.0 \\
\hline 5_15 & 1553 & 40.5 & 892 & 33.0 \\
\hline $16-25$ & 1469 & 35.5 & 1483 & 34.1 \\
\hline$>25$ & 3328 & 40.7 & 3385 & 39.0 \\
\hline Missing & 36 & 19.4 & 31 & 29.0 \\
\hline
\end{tabular}

Table 4 Patient-reported after-hours access to care (very easy and somewhat easy) in the year patients responded to the HCES by physicians' characteristics identified on March 31st, 2015

\begin{tabular}{|c|c|c|c|c|}
\hline & \multicolumn{2}{|c|}{ Interprofessional Teams } & \multicolumn{2}{|c|}{ Non-interprofessional Teams } \\
\hline & Denominator & Percentage & Denominator & Percentage \\
\hline \multicolumn{5}{|c|}{ Physicians characteristics } \\
\hline \multicolumn{5}{|l|}{ Sex } \\
\hline Female & 4917 & 32.3 & 4246 & 34.5 \\
\hline Male & 7769 & 29.9 & 7145 & 34.0 \\
\hline Missing & 83 & 27.7 & 65 & 29.2 \\
\hline \multicolumn{5}{|l|}{ Age group } \\
\hline$<40$ & 1385 & 31.2 & 829 & 36.4 \\
\hline $40-64$ & 8542 & 31.3 & 7605 & 33.9 \\
\hline$>64$ & 2523 & 29.4 & 2791 & 34.6 \\
\hline Missing & 319 & 26.6 & 231 & 29.0 \\
\hline \multicolumn{5}{|c|}{ Country of medical graduation Canada } \\
\hline No & 2324 & 27.6 & 2572 & 33.7 \\
\hline Yes & 10,126 & 31.6 & 8653 & 34.4 \\
\hline Missing & 319 & 26.6 & 231 & 29.0 \\
\hline \multicolumn{5}{|c|}{ Years in practice } \\
\hline$<5$ & 285 & 27.0 & 205 & 34.1 \\
\hline $5-15$ & 2907 & 31.9 & 1679 & 33.7 \\
\hline $16-25$ & 2865 & 31.7 & 2791 & 33.0 \\
\hline$>25$ & 6629 & 30.1 & 6716 & 34.8 \\
\hline Missing & 83 & 27.7 & 65 & 29.2 \\
\hline
\end{tabular}


Table 5 Patient-reported timely access to care (same/next day) by patients' characteristics identified at the year they have responded to the HCES

\begin{tabular}{|c|c|c|c|c|}
\hline & \multicolumn{2}{|c|}{ Interprofessional Teams } & \multicolumn{2}{|c|}{ Non-interprofessional Teams } \\
\hline & Denominator & Weighted Percentage & Denominator & Weighted Percentage \\
\hline Overall self-reported timely Access to care & 6537 & 39.9 & 5901 & 39.1 \\
\hline \multicolumn{5}{|l|}{ Sex } \\
\hline Female & 4159 & 40.5 & 3681 & 39.6 \\
\hline Males & 2378 & 38.8 & 2220 & 38.2 \\
\hline Missing & 0 & - & 0 & - \\
\hline \multicolumn{5}{|l|}{ Age group, yr. } \\
\hline $16-44$ & 1964 & 41.0 & 1840 & 38.1 \\
\hline $45-64$ & 2781 & 36.8 & 2467 & 38.1 \\
\hline $65+$ & 1680 & 44.5 & 1479 & 42.5 \\
\hline Missing & 112 & 40.0 & 115 & 43.1 \\
\hline \multicolumn{5}{|l|}{ New OHIP registrants (within 10 years) } \\
\hline No & 6351 & 39.9 & 5659 & 38.6 \\
\hline Yes & 180 & 36.7 & 238 & 47.1 \\
\hline \multicolumn{5}{|l|}{ Income quintile } \\
\hline 1 (low) & 1030 & 37.6 & 862 & 35.8 \\
\hline 2 & 1239 & 39.7 & 1132 & 40.3 \\
\hline 3 & 1340 & 41.1 & 1193 & 37.1 \\
\hline 4 & 1419 & 38.9 & 1254 & 37.9 \\
\hline 5 (high) & 1500 & 41.2 & 1445 & 42.2 \\
\hline Missing & 9 & 29.3 & 15 & 32.9 \\
\hline \multicolumn{5}{|l|}{ Rurality Index of Ontario } \\
\hline Largest Urban (0) & 2010 & 42.8 & 2133 & 42.9 \\
\hline Large urban (1 to 9) & 1276 & 42.2 & 2077 & 37.1 \\
\hline Small-urban (10 to 39 ) & 2375 & 39.1 & 1312 & 36.1 \\
\hline Rural $(\geq 40)$ & 832 & 30.1 & 345 & 29.5 \\
\hline Missing & 44 & 18.7 & 34 & 31.3 \\
\hline \multicolumn{5}{|l|}{ Resource utilization band (RUB) } \\
\hline 1 & 234 & 42.1 & 167 & 42.0 \\
\hline 2 & 868 & 38.4 & 700 & 36.7 \\
\hline 3 & 3625 & 39.5 & 3421 & 39.3 \\
\hline 4 & 1172 & 42.6 & 1114 & 39.2 \\
\hline 5 (very high user) & 508 & 40.5 & 425 & 41.7 \\
\hline Non-user and Missing & 130 & 44.4 & 74 & 24.1 \\
\hline \multicolumn{5}{|l|}{ Patients with Chronic disease } \\
\hline \multicolumn{5}{|l|}{$2+$ Co-morbidity } \\
\hline No & 3221 & 38.2 & 2817 & 37.8 \\
\hline Yes & 3316 & 41.8 & 3084 & 40.4 \\
\hline \multicolumn{5}{|l|}{$3+$ comorbidities } \\
\hline No & 4602 & 40.0 & 4087 & 37.8 \\
\hline Yes & 1935 & 39.4 & 1814 & 42.6 \\
\hline \multicolumn{5}{|l|}{$4+$ comorbidities } \\
\hline No & 5505 & 39.7 & 4931 & 38.6 \\
\hline Yes & 1032 & 41.1 & 970 & 41.9 \\
\hline \multicolumn{5}{|l|}{$5+$ comorbidities } \\
\hline No & 6022 & 39.8 & 5444 & 38.8 \\
\hline Yes & 515 & 40.8 & 457 & 43.1 \\
\hline
\end{tabular}


Table 6 Patient-reported after-hours to care (very easy and somewhat easy) by patients' characteristics identified in the year they have responded to the HCES

\begin{tabular}{|c|c|c|c|c|}
\hline & \multicolumn{2}{|c|}{ Interprofessional Teams } & \multicolumn{2}{|c|}{$\begin{array}{l}\text { HCES Respondents in Non-interprofessional } \\
\text { Teams }\end{array}$} \\
\hline & Denominator & Weighted Percentage & Denominator & Weighted Percentage \\
\hline Overall patient-reported after-hours access to care & 12,769 & 30.8 & 11,456 & 35.2 \\
\hline \multicolumn{5}{|l|}{ Patients characteristics } \\
\hline \multicolumn{5}{|l|}{ Sex } \\
\hline Female & 7584 & 33.4 & 6765 & 37.0 \\
\hline Males & 5185 & 30.9 & 4691 & 32.8 \\
\hline \multicolumn{5}{|l|}{ Missing } \\
\hline \multicolumn{5}{|l|}{ Age group, yr. } \\
\hline $16-44$ & 3703 & 38.9 & 3544 & 39.3 \\
\hline $45-64$ & 5199 & 30.9 & 4602 & 34.2 \\
\hline $65+$ & 3575 & 26.0 & 3051 & 31.1 \\
\hline Missing & 292 & 28.5 & 259 & 33.9 \\
\hline \multicolumn{5}{|l|}{ New OHIP registrants (within 10 years) } \\
\hline Yes & 346 & 30.4 & 445 & 40.0 \\
\hline NO & 12,410 & 32.4 & 10,997 & 35.0 \\
\hline Missing & 13 & 42.8 & 14 & 47.9 \\
\hline \multicolumn{5}{|l|}{ Income quintile } \\
\hline 1 (low) & 2038 & 32.3 & 1718 & 34.5 \\
\hline 2 & 2427 & 29.6 & 2187 & 33.8 \\
\hline 3 & 2655 & 32.1 & 2268 & 33.2 \\
\hline 4 & 2777 & 34.7 & 2511 & 35.6 \\
\hline 5 (high) & 2849 & 32.4 & 2745 & 37.8 \\
\hline Missing & 23 & 44.4 & 27 & 33.2 \\
\hline \multicolumn{5}{|l|}{ Rurality Index of Ontario } \\
\hline Largest Urban (0) & 3700 & 38.3 & 3931 & 37.8 \\
\hline Large urban (1 to 9) & 2344 & 41.5 & 4010 & 39.0 \\
\hline Small-urban (10 to 39) & 4752 & 28.0 & 2699 & 28.6 \\
\hline Rural $(\geq 40)$ & 1852 & 18.4 & 746 & 23.2 \\
\hline Missing & 121 & 23.4 & 70 & 24.6 \\
\hline \multicolumn{5}{|l|}{ Resource utilization band (RUB) } \\
\hline 1 & 609 & 33.4 & 457 & 38.4 \\
\hline 2 & 2073 & 35.8 & 1771 & 37.9 \\
\hline 3 & 6671 & 30.9 & 6334 & 35.1 \\
\hline 4 & 2013 & 32.0 & 1845 & 34.4 \\
\hline 5 & 816 & 30.8 & 671 & 33.7 \\
\hline Non-user and Missing & 587 & 39.6 & 378 & 37.7 \\
\hline \multicolumn{5}{|l|}{ Patients with Chronic disease } \\
\hline \multicolumn{5}{|l|}{$2+$ Co-morbidity } \\
\hline No & 6732 & 34.0 & 5875 & 36.1 \\
\hline Yes & 6037 & 30.1 & 5581 & 34.2 \\
\hline \multicolumn{5}{|l|}{$3+$ comorbidities } \\
\hline No & 9322 & 33.2 & 8274 & 35.3 \\
\hline Yes & 3447 & 29.4 & 3182 & 35.0 \\
\hline
\end{tabular}


Table 6 Patient-reported after-hours to care (very easy and somewhat easy) by patients' characteristics identified in the year they have responded to the HCES (Continued)

\begin{tabular}{|c|c|c|c|c|}
\hline & \multicolumn{2}{|c|}{ Interprofessional Teams } & \multicolumn{2}{|c|}{$\begin{array}{l}\text { HCES Respondents in Non-interprofessional } \\
\text { Teams }\end{array}$} \\
\hline & Denominator & Weighted Percentage & Denominator & Weighted Percentage \\
\hline \multicolumn{5}{|c|}{$4+$ comorbidities } \\
\hline No & 10,963 & 32.6 & 9784 & 35.2 \\
\hline Yes & 1806 & 30.2 & 1672 & 35.7 \\
\hline \multicolumn{5}{|c|}{$5+$ comorbidities } \\
\hline No & 11,886 & 32.5 & 10,672 & 35.0 \\
\hline Yes & 883 & 29.8 & 784 & 38.4 \\
\hline
\end{tabular}

in non-interprofessional teams. Interprofessional teams compared to non-interprofessional team physicians had: fewer patients per physician (mean $=1366$ versus 1555, respectively); more female physicians (46.3\% versus $43.8 \%$, respectively); more physicians in the younger age group under 40 years old ( $15.4 \%$ versus $9.3 \%$, respectively); more physicians who were Canadian graduates $(80.9 \%$ versus $74.4 \%$, respectively); fewer years in practice $(29.1 \%$ versus $17.6 \%$, respectively in the 5 to 15 years category) (Table 1 ).

There were 10,102 HCES respondents included in this study of whom $42.4 \%$ were in interprofessional teams and $42.3 \%$ were in non-interprofessional teams. Interprofessional as compared to non-interprofessional teams had fewer HCES respondents who were immigrants (3.1\% versus $5.1 \%$, respectively); fewer HCES respondents in the highest income quintile (23.3\% versus $26.4 \%$, respectively); more HCES respondents residing in rural areas $(14.2 \%$ versus $5.8 \%$, respectively) and fewer patients with two or more comorbidities (42.6\% versus $44.3 \%$, respectively) (Table 2).

\section{Univariate analysis}

Patient-reported timely access to care and after-hours access to care comparing HCES respondents in interprofessional teams versus non-interprofessional teams HCES respondents in interprofessional teams were slightly more likely to report timely access to care (same/next day) when compared to patients in non-interprofessional teams (39.9\% versus 39.1\%). HCES respondents in interprofessional teams were less likely to report easy or somewhat easy access to after-hours care compared to patients in non-interprofessional teams (30.8\% versus 35.2\%). The results stratified by physicians charateristics are presented in Tables 3 and 4 . Tables 5 and 6 present the results stratified by patient characteristics.

\section{Patient-reported walk-in clinic visits and emergency department use comparing HCES respondents in} interprofessional teams versus non-interprofessional teams HCES respondents in interprofessional teams reported a lower percent of walk-in clinic visits compared to patients in non-interprofessional teams $(19.7 \%$ versus
$28.2 \%$, respectively) (Table 7). A higher percent of HCES respondents in interprofessional teams had emergency department visits as compared to patients in noninterprofessional teams $(26.7 \%$ versus $23.5 \%$, respectively) (Table 8 ). The results stratified by physician charateristics are presented in Tables 9 and 10.

\section{Multivariate analysis \\ Association between enrollment in an interprofessional team and the outcomes}

When we examined timely access to care while adjusting for physician group, physician and patient characteristics, we found that being in an interprofessional team was associated with an increased odd of patient-reported timely (same/next day) access to care of $12 \%(\mathrm{OR}=1.12$ $\mathrm{CI}=1.00$ to $1.24 p$-value 0.0436$)$ and decreased odds of self-reporting walk-in clinic use of $16 \%(\mathrm{OR}=0.84 \mathrm{CI}=$ 0.75 to $0.94 p$-value 0.0019$)$. We did not find significant differences after adjustment between interprofessional and non-interprofessional teams in patient-reported after-hours access to care or in emergency department use (Table 11).

When we stratified the analyses by sex and by rurality, we did not find a consistent pattern across the outcomes when comparing interprofessional teams with noninterprofessional teams (results not included but can be made available upon request).

\section{Discussion}

We linked the HCES to administrative databases to examine the association between receiving care from interprofessional primary care teams and patient-reported timely access and after-hours access to care, patientreported use of walk-in clinics and emergency department use. We found that HCES respondents receiving care from interprofessional teams self-reported more timely access to care and less walk-in clinic use. We did not find a significant difference in patient-reported afterhours access to care or in emergency department visits.

The professional management and clinical structure available through interprofessional teams, such as having 
Table 7 Patient-reported walk-in clinic by patients' characteristics identified at the year they have responded to the HCES

\begin{tabular}{lllllll}
\hline & \multicolumn{2}{l}{ Interprofessional Teams } & & \multicolumn{2}{l}{ Non-Interprofessional Teams } \\
\cline { 2 - 3 } & Denominator & Weighted Percentage & & Denominator & Weighted Percentage \\
\hline Overall patient-reported walk-in clinic & 12,988 & 19.7 & 11,648 & 28.2
\end{tabular}

Patients characteristics

Sex

Males

Female

Missing

Age group, yr.

$16-44$

45-64

65-84

$85+$

Missing

New OHIP registrants (within 10 years)

Yes

No

Missing

Income quintile

1 (low)

2

3

4

5 (high)

Missing

Rurality Index of Ontario

Largest Urban (0)

Large urban (1 to 9)

Small-urban (10 to 39 )

Rural $(\geq 40)$

Missing

Resource utilization band (RUB)

1

2

3

4

5

Non-user and Missing

Patients with Chronic disease

$2+$ Co-morbidity

Yes

No

$3+$ comorbidities

Yes

No

\section{0 \\ 7678}

0

3819
5272
3602
295
0

0

\section{5}

12,620

13

2089

2468

2697

2822

2888

24

\section{9}

2388

4823

1892

126

629

2128

6746

2031

823

631

6096

6892

3482

9506
17.7

21.2

$-$

29.5

17.1

11.3

10.1

$-$

$\begin{array}{ll}4792 & 26.1 \\ 6856 & 29.7 \\ 0 & -\end{array}$

3653

37.6

4661

27.4

3071

15.9

263

14.9

0

23.6

19.6

21.0

460

34.2

11,174

27.8

14

40.8

19.2

1764

27.1

17.4

2228

27.6

2295

28.7

2550

30.4

2784

26.8

27

36.3

12.6

21.8

4000

30.2

4078

34.8

2737

19.8

763

10.9

9.3

11.2

70

34.9

18.5

17.4

471

26.8

1802

27.8

20.2

23.0

6417

29.6

1869

30.9

674

20.6

18.5

415

25.7

5628

25.9

6020

30.0

21.4

16.8

3207

24.7

8441

29.3 
Table 7 Patient-reported walk-in clinic by patients' characteristics identified at the year they have responded to the HCES (Continued)

\begin{tabular}{|c|c|c|c|c|}
\hline & \multicolumn{2}{|c|}{ Interprofessional Teams } & \multicolumn{2}{|c|}{ Non-Interprofessional Teams } \\
\hline & Denominator & Weighted Percentage & Denominator & Weighted Percentage \\
\hline \multicolumn{5}{|c|}{ 4+ comorbidities } \\
\hline Yes & 1828 & 17.0 & 1686 & 22.7 \\
\hline No & 11,160 & 20.1 & 9962 & 28.9 \\
\hline \multicolumn{5}{|c|}{ 5+ comorbidities } \\
\hline Yes & 894 & 17.3 & 791 & 20.1 \\
\hline No & 12,094 & 19.9 & 10,857 & 28.7 \\
\hline
\end{tabular}

an Executive Director and allied health professionals can theoretically support access to care.

Although more timely access to care among patients in interprofessional teams is not an expectation in the contractual agreement between teams and the Ministry of Health, previous evidence indicates that enhanced interprofessional team structure can support the availability of the primary care provider by shifting some of their duties to other team members [28-33]. The evaluations of Patient-Centered Medical Homes in the United States related to timely access to care suggest that greater availability of providers can free more of their time for patient encounters [34]. Our findings of generally low timely access to care are comparable to other reports that found only $43 \%$ of Canadians report that they were able to have same- or next-day appointment at their regular place of care and identified that Canada continues to perform below the average on timely access to care when compared to other counties included in the Commonwealth Fund International Health Surveys [24].

Our findings showed a non-significant difference in patient-reported after-hours access to care between interprofessional and non-interprofessional teams. The provision of after-hours care is an expectation that all FHOs need to meet as part of their contractual agreement with the Ministry of Health [32]. Although some interprofessional teams operate out of multiple locations, the after-hours services only need to be offered at one location, which may not be convenient for many of the enrolled patients. Also, only one physician is required to be available during each after-hours block which might not be sufficient evening and weekend availability to meet patients' needs. Previous evidence that compared a slightly different after-hours access to care measure (asking if respondents providers have an after-hours clinic as opposed how easy or difficult was it to get care without going to the emergency department) found that respondents in interprofessional teams self-reported more after-hours access to care [18].

Although both interprofessional and noninterprofessional teams get penalised equally if their patients visit a walk-in clinic, our finding of significantly lower patient-reported walk-in clinic visits by HCES respondent among interprofessional teams may be explained by the higher patient-reported timely access to care in interprofessional teams, which can contribute to the lower walk-in clinic use. Patients may be less likely to seek care elsewhere if their provider is accessible to them in a timely manner. Additionally, the enhanced administrative structure of interprofessional teams can support reinforcing to patients the need to refrain from walk-in visits as part of being on the group roster. Our findings of a non-significant difference in emergency department use between interprofessional and noninterprofessional teams is consistent with evidence from Canada that looked at utilization in relation to interprofessional team-based care and found differences in quality but not in healthcare utilization $[19,20,35,36]$.

Some of our findings are not fully consistent with an Ontario provincial analysis where throughout the investigated years (2014 to 2017) timely access to care ranged between 44.3 and $39.9 \%$ (compared to $39.5 \%$ in our study population), easy or somewhat easy after-hours access to care ranged between 48.0 and $46.0 \%$ (vs. 33\% in our sample) and walk-in clinic use ranged between 29.6 and $30.5 \%$ (vs. $24 \%$ in our study) [37]. Those differences can be explained by the slightly different timeframe, inclusion of respondents from all primary care models and slightly larger sample that includes people who declined to have their data linked (6\%) for the provincial analysis. Additionally, for the timely access to care question, the provincial analysis included respondents with and without a family doctor whereas our study includes only respondents with a family doctor. Through a personal communication with the Ministry of Health representative who is responsible for the survey, we have confirmed that our study results can be mainly explained by those differences.

Interprofessional teams in Ontario had access to several quality improvement initiatives that hypothetically can contribute to improved outcomes over noninterprofessional teams. The Association of Family 
Table 8 All ED visits by patients' characteristics identified in the year they responded to the HCES

\begin{tabular}{|c|c|c|c|c|}
\hline & \multicolumn{2}{|c|}{ HCES Respondents in Interprofessional Teams } & \multicolumn{2}{|c|}{ HCES Respondents in Non-interprofessional Teams } \\
\hline & \multicolumn{2}{|l|}{$\geq 1$ ED visits } & \multicolumn{2}{|l|}{$\geq 1$ ED visits } \\
\hline & Denominator & Weighted Percentage & Denominator & Weighted Percentage \\
\hline Overall ED visits & 12,988 & 26.7 & 11,648 & 23.5 \\
\hline \multicolumn{5}{|l|}{ Sex } \\
\hline Males & 5310 & 26.7 & 4792 & 22.9 \\
\hline Female & 7678 & 26.7 & 6856 & 23.9 \\
\hline Missing & 0 & - & 0 & - \\
\hline
\end{tabular}

Age group, yr.

$\begin{array}{ll}16-44 & 3819 \\ 45-64 & 5272 \\ 65-84 & 3602 \\ 85+ & 295 \\ \text { Missing } & 0\end{array}$

26.8
24.1
29.2
40.0
-

$\begin{array}{ll}3653 & 22.3 \\ 4661 & 21.8 \\ 3071 & 26.1 \\ 263 & 38.4 \\ 0 & -\end{array}$

New OHIP registrants (within 10 years)

\begin{tabular}{|c|c|c|c|c|}
\hline Yes & 355 & 20.3 & 460 & 22.0 \\
\hline No & 12,620 & 26.9 & 11,174 & 23.6 \\
\hline
\end{tabular}

Income quintile

$\begin{array}{lllll}1 \text { (low) } & 2089 & 33.3 & 1764 & 27.7 \\ 2 & \mathrm{D} / \mathrm{S} & \mathrm{D} / \mathrm{S} & \mathrm{D} / \mathrm{S} & \mathrm{D} / \mathrm{S} \\ 3 & 2697 & 26.4 & 2295 & 23.8 \\ 4 & 2822 & 24.8 & 2550 & 21.9 \\ 5 \text { (high) } & 2888 & 22.6 & 2784 & 21.6 \\ \text { Missing } & \mathrm{D} / \mathrm{S} & \mathrm{D} / \mathrm{S} & \mathrm{D} / \mathrm{S} & \mathrm{D} / \mathrm{S}\end{array}$

\section{Rurality Index of Ontario}

Largest Urban (0)
Large urban (1 to 9)
Small-urban (10 to 39)
Rural ( $\geq 40$ )
Missing

$763 \quad 37.5$

Resource utilization band (RUB)

$\begin{array}{ll}1 & 629 \\ 2 & 2128 \\ 3 & 6746 \\ 4 & 2031 \\ 5 \text { (very high user) } & 823 \\ \text { Non-user and Missing } & 631\end{array}$

Patients with Chronic disease

$\begin{array}{ll}2+\text { Co-morbidity } & \\ \text { Yes } & 6096 \\ \text { No } & 6892 \\ 3+\text { comorbidities } & \\ \text { Yes } & 3482 \\ \text { No } & 9506 \\ \text { 4+ comorbidities } & \end{array}$

19.2
25.7
34.6
48.5
15.5

$\begin{array}{ll}471 & 15.7 \\ 1802 & 15.2 \\ 6417 & 22.7 \\ 1869 & 31.7 \\ 674 & 42.7 \\ 415 & 13.5\end{array}$

4+ comorbidities 
Table 8 All ED visits by patients' characteristics identified in the year they responded to the HCES (Continued)

\begin{tabular}{|c|c|c|c|c|}
\hline & \multicolumn{2}{|c|}{ HCES Respondents in Interprofessional Teams } & \multicolumn{2}{|c|}{ HCES Respondents in Non-interprofessional Team } \\
\hline & \multicolumn{2}{|l|}{$\geq 1 \mathrm{ED}$ visits } & \multicolumn{2}{|l|}{$\geq 1$ ED visits } \\
\hline & Denominator & Weighted Percentage & Denominator & Weighted Percentage \\
\hline Yes & 1828 & 40.6 & 1686 & 37.9 \\
\hline No & 11,160 & 24.4 & 9962 & 21.0 \\
\hline \multicolumn{5}{|c|}{$5+$ comorbidities } \\
\hline Yes & 894 & 47.0 & 791 & 41.6 \\
\hline No & 12,094 & 25.2 & 10,857 & 22.2 \\
\hline
\end{tabular}

D/S Data suppressed where counts are between 1 and 5 ; additional suppression may be applied where counts are greater than 5 to prevent residual disclosure of suppressed values-in compliant with the Personal Health Information Protection Act (PHIPA) privacy legislation

Health Teams of Ontario through an initiative called Data to Decisions (D2D) supported interprofessional teams in informing quality improvement through performance measurement. D2D was made possible through the investment in more than 30 Quality Improvement Decision Support Specialists (QIDS Specialists) across Ontario to help interprofessional teams to access and use better data to improve care [38]. Timely access to care and emergency department use were among the measurement areas monitored through this initiative [39]. The Quality Improvement and Innovation Partnership (QIIP) was another province wide qualityimprovement program implemented between 2008 and 2010 to support interprofessional teams to improve the care they provide [40]. The learning collaboratives used the Institute for Healthcare Improvement's Breakthrough Series learning model and interprofessional teams were provided with a quality improvement coach who supported and mentored participants throughout the program [41]. Improved access to care was one of

Table 9 Patient-reported walk-in clinic use in the year patients responded to the HCES by physicians' characteristics identified on March 31st, 2015

\begin{tabular}{|c|c|c|c|c|}
\hline & \multicolumn{2}{|c|}{ Interprofessional Teams } & \multicolumn{2}{|c|}{ Non-interprofessional Teams } \\
\hline & Denominator & Percentage & Denominator & Percentage \\
\hline \multicolumn{5}{|c|}{ Physicians characteristics } \\
\hline \multicolumn{5}{|l|}{ Sex } \\
\hline Male & 7909 & 17.3 & 7279 & 26.1 \\
\hline Female & 4994 & 20.3 & 4302 & 28.8 \\
\hline Missing & 85 & 17.6 & 67 & 23.9 \\
\hline \multicolumn{5}{|l|}{ Age group } \\
\hline$<40$ & 1418 & 19.3 & 842 & 27.8 \\
\hline $40-64$ & 8670 & 18.7 & 7717 & 26.8 \\
\hline$>64$ & 2573 & 17.4 & 2852 & 28.1 \\
\hline Missing & 327 & 16.5 & 237 & 20.7 \\
\hline \multicolumn{5}{|c|}{ Country of medical graduation Canada } \\
\hline Yes & 10,286 & 18.2 & 8771 & 26.3 \\
\hline No & 2375 & 19.8 & 2640 & 30.3 \\
\hline Missing & 327 & 16.5 & 237 & 20.7 \\
\hline \multicolumn{5}{|c|}{ Years in practice } \\
\hline$<5$ & 294 & 17.3 & 210 & 20.5 \\
\hline 5_15 & 2971 & 19.1 & 1703 & 27.2 \\
\hline $16-25$ & 2903 & 19.7 & 2835 & 26.7 \\
\hline$>25$ & 6735 & 17.7 & 6833 & 27.4 \\
\hline Missing & 85 & 17.6 & 67 & 23.9 \\
\hline
\end{tabular}


Table 10 All Emergency Department (ED) visits in the year patients responded to the HCES by physicians' characteristics identified on March 31st 2015

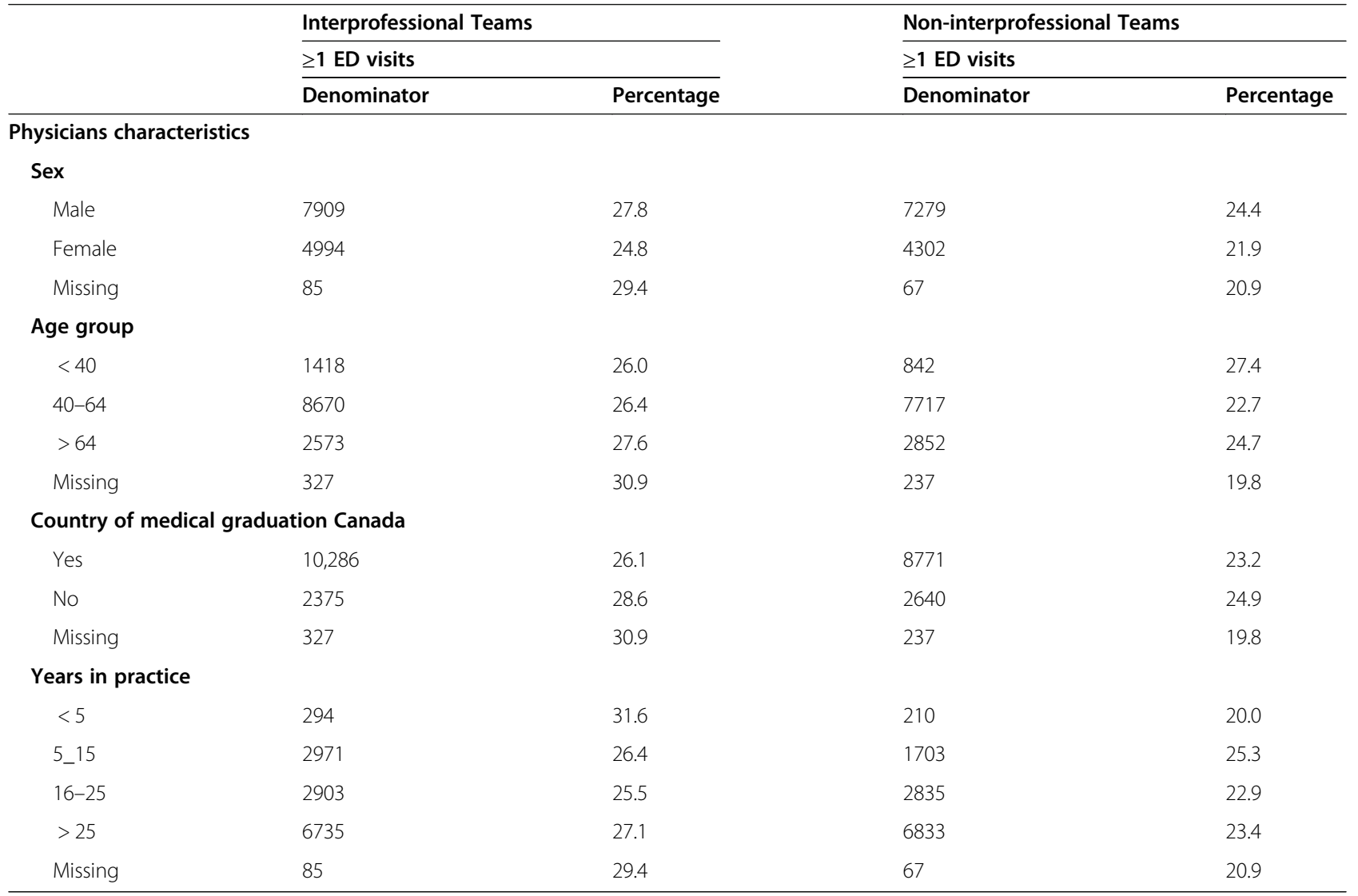

the supported quality improvement areas through QIIP [9]. Those investments should theoretically be reflected in better outcomes among interprofessional teams. The government's first priority in establishing interprofessional teams was to increase access to primary care and health services utilization [32]. Our results show that interprofessional teams perform better than noninterprofessional teams in some but not all aspects related to access to care and health services utilization.

Our study has limitations. First, this is an observational study that cannot address causation. It is also cross-sectional so it is not possible to distinguish whether the outcomes examined were pre-existing or were the result of joining or not joining an interprofessional team. Self-reported timely and after-hours access to care are subject to limitations as measures of performance, respondent recall bias being one of them. People living in institutions, people with non-residential phone numbers, and people with invalid/missing household addresses in the Registered Persons Database (RPDB) are not captured in the HCES. Respondents who were unable to speak English or French or were not healthy enough (physically or mentally) to complete the interview were not surveyed. Second, there are other unmeasured factors that might contribute to the decision of having a walk-in clinic visit or using the emergency department that this study cannot capture. These could include personal preference or judgment during the time the service was needed. Third, access to care can be measured in many different ways. The access questions we investigated in this study provide a specific perspective restricted to timely and after-hours access to care. Previous evidence suggests that different measures of timely access are needed to understand health care system performance. ${ }^{50}$ Fourth, joining interprofessional team-based care was voluntary and our findings could be influenced by some unmeasured factors for physicians who chose to join this model of primary care delivery. Fifth, team composition in terms of allied healthcare professional was not available through administrative databased. Nonetheless, we aimed to capture all measured factors that can be traced through administrative databases. Finally, administrative databases have not been originally collected for research purposes, which presents a limitation in generating and interpreting the information. However, all the databases used for deriving the emergency department measure used in this study have been validated in the Ontario context. 
Table 11 Association between enrolment in an interprofessional team-based model and timely access, after-hours access to care, walk-in clinic use and emergency department visits in the year responded to the survey

\begin{tabular}{|c|c|c|c|c|}
\hline \multirow[b]{3}{*}{ Unadjusted (null model) } & \multicolumn{4}{|c|}{ Timely access to care Reference: non-interprofessional teams } \\
\hline & \multirow{2}{*}{$\begin{array}{l}\text { OR } \\
1.03\end{array}$} & \multicolumn{2}{|l|}{$95 \% \mathrm{Cl}$} & \multirow{2}{*}{$\begin{array}{l}P \text {-Value } \\
0.6764\end{array}$} \\
\hline & & 0.91 & 1.15 & \\
\hline \multicolumn{5}{|l|}{ †Adjusted for: } \\
\hline Physician group characteristics & 1.01 & 0.90 & 1.13 & 0.8397 \\
\hline Group and physicians' characteristics & 1.02 & 0.92 & 1.14 & 0.7041 \\
\hline \multirow[t]{3}{*}{ Physician group, physician and patients } & 1.12 & 1.00 & 1.24 & $0.0436^{*}$ \\
\hline & \multicolumn{4}{|c|}{$\begin{array}{l}\text { After-hours care at the year responded to the survey } \\
\text { Reference: non-interprofessional teams }\end{array}$} \\
\hline & OR & $95 \% \mathrm{Cl}$ & & P-Value \\
\hline Unadjusted (null model) & 0.87 & 0.79 & 0.96 & $0.0068^{*}$ \\
\hline \multicolumn{5}{|l|}{ †Adjusted for: } \\
\hline Physician group characteristics & 0.81 & 0.73 & 0.89 & $<0.0001^{*}$ \\
\hline Group and physicians' characteristics & 0.81 & 0.73 & 0.90 & $<0.0001^{*}$ \\
\hline \multirow[t]{3}{*}{ Physician group, physician and patients } & 1.01 & 0.91 & 1.12 & 0.8251 \\
\hline & \multicolumn{4}{|c|}{$\begin{array}{l}\text { Walk-in clinic visits at the year responded to the survey } \\
\text { Reference: non-interprofessional teams }\end{array}$} \\
\hline & OR & $95 \% \mathrm{Cl}$ & & $P$-Value \\
\hline Unadjusted (null model) & 0.63 & 0.57 & 0.69 & $<0.001^{*}$ \\
\hline \multicolumn{5}{|l|}{ †Adjusted for: } \\
\hline Physician group characteristics & 0.67 & 0.60 & 0.74 & $<0.001^{*}$ \\
\hline Group and physicians' characteristics & 0.68 & 0.61 & 0.76 & $<0.001^{*}$ \\
\hline \multirow[t]{3}{*}{ Physician group, physician and patients } & 0.84 & 0.75 & 0.94 & $0.0019^{*}$ \\
\hline & \multicolumn{4}{|c|}{$\begin{array}{l}\text { Emergency department uses at the year responded to the survey } \\
\text { Reference: non-interprofessional teams }\end{array}$} \\
\hline & OR & $95 \% \mathrm{Cl}$ & & $P$-Value \\
\hline Unadjusted (null model) & 1.17 & 1.08 & 1.28 & $<0.0002^{*}$ \\
\hline \multicolumn{5}{|l|}{ †Adjusted for: } \\
\hline Physician group characteristics & 1.20 & 1.10 & 1.31 & $<0.001^{*}$ \\
\hline Group and physicians' characteristics & 1.20 & 1.10 & 1.30 & $<0.001^{*}$ \\
\hline Physician group, physician and patients & 1.05 & 0.95 & 1.15 & 0.3234 \\
\hline
\end{tabular}

${ }^{*} p$-value significant $<0.05$

† Adjustment used physician groups and physicians' characteristics identified on March 31st, 2015 and patients' characteristics at the year they have responded to the HCES

\section{Conclusion}

Ontario has made a major investment in interprofessional team-based care. As compared to patients in non-interprofessional teams, patients in interprofessional teams self-reported more timely access to care and less walk-in clinic use but there was no significant difference in self-reported access to after hours to care and in emergency department use. Our findings can inform other jurisdictions aiming to expand voluntary participation in interprofessional team-based primary care regarding expectations about the relationship between primary care policy, organization and delivery and patient experience and health services utilization. Careful consideration should be given to contractual and policy levers that can incentivise interprofessional team-based care in delivering on intended outcomes such as improving health services utilization.

\section{Abbreviations}

HCES: Health care experience survey; FHO: Family health organization; OHIP: Ontario health insurance plan; $\mathrm{MOH}$ : Ministry of health; NACR S: National ambulatory care reporting system; RIO: Rurality index of ontario; QIDS: Quality improvement decision support specialists; QIIP: Quality improvement and innovation partnership; RPDB: Registered persons database

\section{Acknowledgements}

Not applicable. 


\section{Authors' contributions}

WHA: Conceptualization, Methodology, Formal Analysis, Writing-Original Draft. RM: Conceptualization, Methodology, Formal Analysis, Writing-Review \& Editing.BH: Conceptualization, Methodology, Writing-Review \& Editing, Supervision. WPW: Conceptualization, Methodology, Writing-Review \& Editing, Supervision. RHG: Conceptualization, Methodology, Writing-Review \& Editing, Supervision. All authors have read and approved the manuscript.

\section{Funding}

This study was supported by ICES, which is funded by an annual grant from the Ontario Ministry of Health and Long-Term Care (MOHLTC). ICES is an independent, non-profit research institute funded by an annual grant from the Ontario Ministry of Health and Long-Term Care (MOHLTC). As a prescribed entity under Ontario's privacy legislation, ICES is authorized to collect and use health care data for the purposes of health system analysis, evaluation and decision support. Secure access to these data is governed by policies and procedures that are approved by the Information and Privacy Commissioner of Ontario. Parts of this material are based on data and information compiled and provided by the Canadian Institute for Health Information $(\mathrm{ClH})$. The analyses, conclusions, opinions and statements expressed herein are solely those of the authors and do not reflect those of the funding or data sources; no endorsement is intended or should be inferred. Richard $\mathrm{H}$. Glazier is supported as a Clinician Scientist in the Department of Family and Community Medicine at St. Michael's Hospital and at the University of Toronto. ICES did not have any influence on the design analysis or interpretation of the results.

\section{Availability of data and materials}

The dataset from this study is held securely in coded form at ICES. While data sharing agreements prohibit ICES from making the dataset publicly available, access may be granted to those who meet pre-specified criteria for confidential access, available at www.ices.on.ca/DAS. The full dataset creation plan and underlying analytic code are available from the authors upon request, understanding that the computer programs may rely upon coding templates or macros that are unique to ICES and are therefore either inaccessible or may require modification.

\section{Declarations}

\section{Ethics approval and consent to participate}

ICES (formerly known as Institute for Clinical Evaluative Sciences) is a prescribed entity under section 45 of Ontario's Personal Health Information Protection Act. Section 45 authorizes ICES to collect personal health information, without consent, for the purpose of analysis or compiling statistical information with respect to the management of, evaluation or monitoring of, the allocation of resources to or planning for all or part of the health system. Projects conducted under section 45 , by definition, do not require review by a Research Ethics Board. This project was conducted under section 45 and access to the data was approved by ICES' Privacy and Legal Office.

\section{Consent for publication}

Not applicable.

\section{Competing interests}

The authors declare that they have no competing interests.

\section{Author details}

${ }^{1}$ Dalla Lana School of Public Health, Toronto, Ontario, Canada. ${ }^{2}$ Institute of Health Policy, Management and Evaluation, University of Toronto, 155 College Street, Toronto, Ontario M5T 3M6, Canada. ${ }^{3}$ Canadian Centre for Health Economics, Toronto, Canada. ${ }^{4}$ Institute for Clinical Evaluative Sciences, Toronto, Canada. ${ }^{5}$ Departments of Family Medicine and Health Research Methods, Evidence and Impact, McMaster University, Hamilton, Canada. ${ }^{6}$ Department of Family and Community Medicine, University of Toronto,

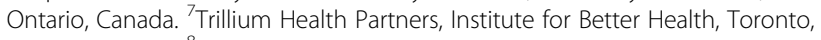
Ontario, Canada. ${ }^{8}$ MAP Centre for Urban Health Solutions, St. Michael's Hospital, Toronto, Canada.
Received: 27 August 2020 Accepted: 1 June 2021

Published online: 14 September 2021

\section{References}

1. Chisholm D, Evans DB. Improving health system efficiency as a means of moving towards universal coverage. World Health Report (2010), Background Paper, 28 [Internet]. 2010. Available: http://www.who.int/hea Ithsystems/topics/financing/healthreport/28UCefficiency.pdf. Accessed 02 February 2016.

2. Berwick DM, Nolan TW, Whittington J. The triple aim: care, health, and cost. Health Aff (Millwood). 2008;27(3):759-69. https://doi.org/10.1377/hlthaff.27.3. 759.

3. Starfield B, Shi L, Macinko J. Contribution of primary care to health systems and health. Milbank Q. 2005;83:457e502.

4. Hutchison B, LEVESQUE JF, Strumpf E, Coyle N. Primary health care in Canada: systems in motion. Milbank Q. 2011;89(2):256-88. https://doi.org/1 0.1111/j.1468-0009.2011.00628.x.

5. Commission on the Future of Health Care in Canada. Building on values: the future of health care in Canada - final report [Internet]. Saskatoon (SK): Government of Canada; 2002. Available from: http://publications.gc.ca/ collections/Collection/CP32-85-2002E.pdf

6. Standing Senate Committee on Social Affairs. Science, and Technology. The health of Canadians — federal role-final report. In: Recommendations for reform [Internet], vol. 6. Ottawa (ON): Parliament of Canada. Available from: http://www.parl.gc.ca/Content/SEN/Committee/372/soci/rep/repoct02vol6-e. htm.

7. Hutchison B, Glazier R. Ontario's primary care reforms have transformed the local care landscape, but a plan is needed for ongoing improvement. Health Affairs. 2013;32(4):695-703. DOl: https://doi.org/https://doi.org/10.13 77/hlthaff.2012.1087,

8. Conference Board of Canada. Improving primary health care through collaboration: briefing 1-Current knowledge about interprofessional teams in Canada. Ottawa (ON): The Board; 2012. p. 2.

9. Rosser WW, Colwill JM, Kasperski J, Wilson L. Progress of Ontario's family health team model: a patient-centered medical home. Ann Fam Med. 2011; 9(2):165-71. https://doi.org/10.1370/afm.1228.

10. Goh TT, Eccles MP. Team climate and quality of care in primary health care: a review of studies using the team climate inventory in the United Kingdom. BMC Res Notes. 2009;2(1):222. https://doi.org/10.1186/17560500-2-222.

11. Canadian Association of Emergency Physicians and National Emergency Nurses Affiliation. Canadian Association of Emergency Physicians and National Emergency Nurses Affiliation (CAEPNENA) joint position statement on emergency department overcrowding. Can J Emerg Med. 2001;3(2):82-4. https://doi.org/10.1017/S1481803500005285.

12. Moskop JC, Sklar DP, Geiderman JM, Schears RM, Bookman KJ. Emergency department crowding, part 1-concept, causes, and moral consequences. Ann Emerg Med. 2009;53(5):605-11. https://doi.org/10.1016/j.a nnemergmed.2008.09.019.

13. Durand AC, Palazzolo S, Tanti-Hardouin N, Gerbeaux P, Sambuc R, Gentile S. Nonurgent patients in emergency departments: rational or irresponsible consumers? Perceptions of professionals and patients. BMC Res Notes. 2012; 5(1):525. https://doi.org/10.1186/1756-0500-5-525.

14. Jaakkimainen RL, Barnsley J, Klein-Geltink J, Kopp A, Glazier RH. Did changing primary care delivery models change performance? A population based study using health administrative data. BMC Fam Pract. 2011;12(1):44. DOI: https://doi.org/https://doi.org/10.1186/1471-2296-12-44.

15. Muldoon L, Dahrouge S, Hogg W, Geneau R, Russell G, Shortt M. Community orientation in primary care practices: results from the comparison of models of primary health Care in Ontario Study. Can Fam Physician. 2010;56(7):676-83 Available at: http:/www.cfp.ca/content/56/7/ 676.short.

16. Glazier RH, Klein-Geltink J, Kopp A, Sibley LM. Capitation and enhanced feefor-service models for primary care reform: a population-based evaluation. Cmaj. 2009;180(11):E72-81. Available at: http://www.cmaj.ca/content/1 80/11/E72.short. https://doi.org/10.1503/cmaj.081316.

17. Kiran T, Victor JC, Kopp A, Shah BR, Glazier RH. The relationship between financial incentives and quality of diabetes care in Ontario, Canada. Diab Care. 2012;35(5):1038-1046.DOl: https://doi.org/https://doi.org/10.2337/ dc11-1402. 
18. Kiran T, Kopp A, Moineddin R, Glazier RH. Longitudinal evaluation of physician payment reform and team-based care for chronic disease management and prevention. CMAJ. 2015;187(17):E494-E502. DOI: https:// doi.org/https://doi.org/10.1503/cmaj.150579.

19. Glazier RH, Hutchison B, Kopp A. Comparison of family health teams to other Ontario primary care models, 2004/05 to 2011/12. Toronto: Institute for Clinical Evaluative Sciences; 2015.

20. Glazier RH, Zagorski BM, Rayner J. Comparison of Primary Care Models in Ontario by Demographics, Case Mix and Emergency Department Use, 2008/ 09 to 2009/10. In: ICES investigative report. Toronto: Institute for Clinical Evaluative Sciences. p. 2012.

21. Ontario Ministry of Finance. Ontario Fact Sheet April 2016 Available from: https://www.fin.gov.on.ca/en/economy/ecupdates/factsheet.html Accessed 31 Dec 2019.

22. Kiran T, Kopp A, Glazier RH. Those left behind from voluntary medical home reforms in Ontario, Canada. Ann Fam Med. 2016;14(6):517-25. https://doi. org/10.1370/afm.2000.

23. Annual Report of the Office of the Auditor General of Ontario: Funding Alternatives for Family Physicians 2011. Available at: https://www.auditor.on. ca/en/content/annualreports/arreports/en11/306en11.pdf.

24. Ministry of Health and Long-Term Care. Primary Health Care Team Fact Sheet. Family Health Organization. May 2007. Available at: https://www.anl com/MOHGUIDE/44\%20Family\%20Health\%20Organization\%20(FHO)\%20Fa ct\%20Sheet.pdf Accessed on July 6, 2020.

25. Kralj B. Measuring rurality -RIO2008 BASIC: methodology and results. Toronto: Ontario Medical Association; 2008.

26. The Johns Hopkins University. The Johns Hopkins ACG System. Accessed March 25, 2015 at http://acg.jhsph.org/index.php

27. McCarthy D, Mueller K, Tillmann I, Fund C. Group health cooperative: reinventing primary care by connecting patients with a medical home. Commonwealth Fund; 2009. https://www.commonwealthfund.org/publica tions/case-study/2009/jul/group-health-cooperativereinventing-primary-careconnecting.

28. Sinsky CA, Willard-Grace R, Schutzbank AM, Sinsky TA, Margolius D, Bodenheimer $T$. In search of joy in practice: a report of 23 high-functioning primary care practices. Ann Fam Med. 2013;11(3):272-8. https://doi.org/10.13 70/afm.1531.

29. Ghorob A, Bodenheimer T. Sharing the care to improve access to primary care N Engl J Med. 2012;366(21):1955-7. https://doi.org/10.1056/NEJMp1202775.

30. Bodenheimer T, Laing BY. The teamlet model of primary care. Ann Fam Med. 2007;5(5):457-61. https://doi.org/10.1370/afm.731.

31. Sinsky CA, Sinsky TA, Althaus D, Tranel J, Thiltgen M. Practice profi le. 'Core teams': nurse-physician partnerships provide patient-centered care at an lowa practice. Health Aff (Millwood). 2010;29(5):966-8.

32. Kiran T, Green ME, DeWit Y, Khan S, Schultz S, Kopp A, et al. Association of physician payment model and team-based care with timely access in primary care: a population-based cross-sectional study. CMAJ open. 2020; 8(2):E328-37. https://doi.org/10.9778/cmajo.20190063.

33. Nielsen M, Olayiwola JN, Grundy P, Grumbach K. The patient-centered medical home's impact on cost \& quality: An annual update of the evidence, 2012-2013. Washington, DC: Patient-Centered Primary Care Collaborative; 2014. p. 37.

34. Canadian Institute for Health Information. How Canada compares: results from the Commonwealth Fund's 2016 international health policy survey of adults in 11 countries. Ottawa, Ontario: $\mathrm{ClHI} ; 2017$.

35. Strumpf E, Ammi M, Diop M, Fiset-Laniel J, Tousignant P. The impact of team-based primary care on health care services utilization and costs: Quebec's family medicine groups. J Health Econ. 2017;55:76-94. DOl: https://doi.org/https://doi.org/10.1016/j.jhealeco.2017.06.009.

36. Ministry of Health and Long-Term Care. Health Care Experience Survey Results. January 2014 to December 2017.

37. Association of Family Health Teams of Ontario. What is a Quality Improvement Decision support Specialist? Available at: https://www.afhto $\mathrm{ca} /$ news-events/news/what-quality-improvement-decision-support-specia list-qidss Accessed on February 2020.

38. Association of Family Health Teams of Ontario. D2D Data Dictionary Available at: https://www.afhto.ca/wp-content/uploads/Data-Dictionary-D2 D-3.0.pdf Accessed on February 2020.

39. Green ME, Harris SB, Webster-Bogaert S, Han H, Kotecha J, Kopp A, et al. Impact of a provincial quality-improvement program on primary health care in Ontario: a population-based controlled before-and-after study. CMAJ open. 2017;5(2):E281-9. https://doi.org/10.9778/cmajo.20160104.

40. American Diabetes Association. The breakthrough series: IHI's collaborative model for achieving breakthrough improvement. Diabetes Spectr. 2004; 17(2):97-101.

41. http://www.hqontario.ca/Portals/0/documents/qi/qi-report-learningcollabora tive1-0909-en.pdf

\section{Publisher's Note}

Springer Nature remains neutral with regard to jurisdictional claims in published maps and institutional affiliations.
Ready to submit your research? Choose BMC and benefit from:

- fast, convenient online submission

- thorough peer review by experienced researchers in your field

- rapid publication on acceptance

- support for research data, including large and complex data types

- gold Open Access which fosters wider collaboration and increased citations

- maximum visibility for your research: over $100 \mathrm{M}$ website views per year

At BMC, research is always in progress.

Learn more biomedcentral.com/submissions 